\title{
Effects of pH on the Shape of Alginate Particles and Its Release Behavior
}

\author{
Jui-Jung Chuang, ${ }^{1}$ Yu-Ya Huang, ${ }^{2}$ Szu-Hsuan Lo, ${ }^{2}$ Tzu-Fang Hsu, ${ }^{2}$ Wen-Ying Huang, \\ Shu-Ling Huang, ${ }^{3}$ and Yung-Sheng $\mathrm{Lin}^{3}$ \\ ${ }^{1}$ Department of Pharmacy, Cheng Ching Hospital, Taichung, Taiwan \\ ${ }^{2}$ Department of Applied Cosmetology and Master Program of Cosmetic Science, Hungkuang University, Taichung, Taiwan \\ ${ }^{3}$ Department of Chemical Engineering, National United University, Miaoli, Taiwan
}

Correspondence should be addressed to Yung-Sheng Lin; linys@nuu.edu.tw

Received 6 September 2016; Revised 26 November 2016; Accepted 5 December 2016; Published 9 January 2017

Academic Editor: Chao Lin

Copyright (C) 2017 Jui-Jung Chuang et al. This is an open access article distributed under the Creative Commons Attribution License, which permits unrestricted use, distribution, and reproduction in any medium, provided the original work is properly cited.

\begin{abstract}
A vast majority of alginate particles exist as spheres in most practical uses, and both the particle shape and size are the key factors dominating the applications and performance of alginate gels. Therefore, it becomes an issue of great interest to investigate the aspheric alginate particles. As the first step, various shaped alginate particles were formed due to various $\mathrm{pH}$ values in gelation solutions. It was experimentally demonstrated that a low $\mathrm{pH}$ brought about an oblate shape, and particularly lower concentrations of both alginate and divalent cations resulted in a flattened oblate shape. $\mathrm{Ba}^{2+}$ acting as a cross-linker had a less impact on the particle shape than $\mathrm{Ca}^{2+}$ due to a higher affinity in alginate intermolecular cross-linking. With a larger surface area, an oblate particle offered a higher release rate than a spheric one.
\end{abstract}

\section{Introduction}

Over the past few decades, utilization of natural polymers for the development of drug delivery systems remained a subject of great interest [1-3]. Natural polymers remain attractive mostly due to their easy availability, cost effectiveness, biodegradability, and biocompatibility [4]. There is a large amount of alginate in our environment [5] and is discovered as the structural components of brown marine algae [6]. Alginate is a linear copolymer consisting of guluronic $(\mathrm{G})$ and mannuronic (M) acid forming regions of $\mathrm{M}$ - and G-blocks and alternating structure (MG-blocks) [7]. Divalent cations such as $\mathrm{Ca}^{2+}$ and $\mathrm{Ba}^{2+}$ bind to the G-blocks of alginate in a highly cooperative manner, such that a gel is formed $[8,9]$. Commonly used in a wide variety of fields, alginate is so far mainly processed into capsules, beads, and fibres [10] and has been frequently used for encapsulation of biologically active agents [11].

A vast majority of alginate particles exist as spheres in either internal [12,13] or external gelation [14-17], but this geometry has some disadvantages when in use [18]. Applications and performance of alginate particles depend upon their shape and size. It becomes an issue of great interest to investigate the effects of aspheric particles in a wide range of scientific fields $[19,20]$, such as tail-shaped [21], mushroom-like [22], and hemispheric [23] particles. Disk-shaped particles showed a better half-life in circulation and precise targeting in mice [24]. Particles of rod shape performed higher adhesion than spheric particles in endothelium [25]. Elliptical disk-shaped particles are not phagocytosed by macrophages [26]. Hence, an issue of aspheric alginate particles deserves to be studied.

In most cases, spheric alginate particles are available by use of a typical droplet formation approach in an attempt to minimize the interfacial free energy between particles and gelation solution $[22,27]$. Scientists look forward to finding a simple way for the synthesis of aspheric alginate particles, and it is indicated that the shape of particles can be easily tuned by the interfacial tension [28]. Accordingly, various oil/water interfaces and polyelectrolyte complexation were 

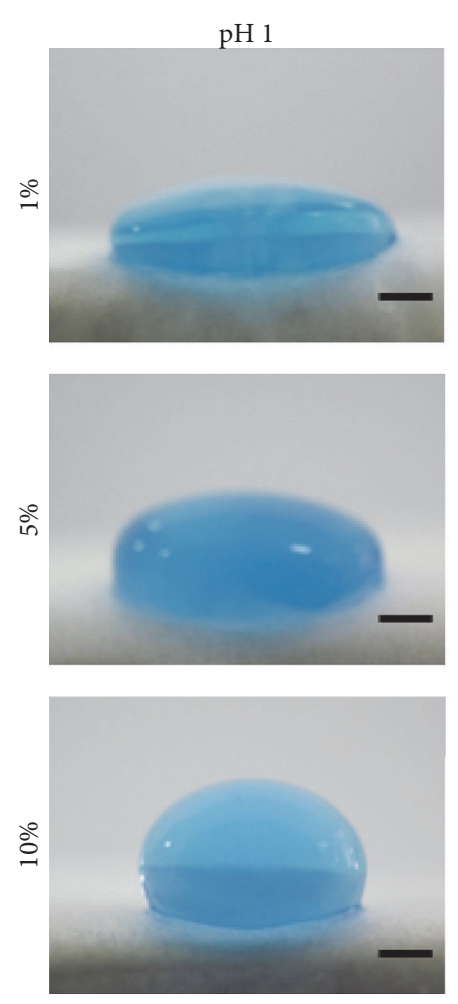
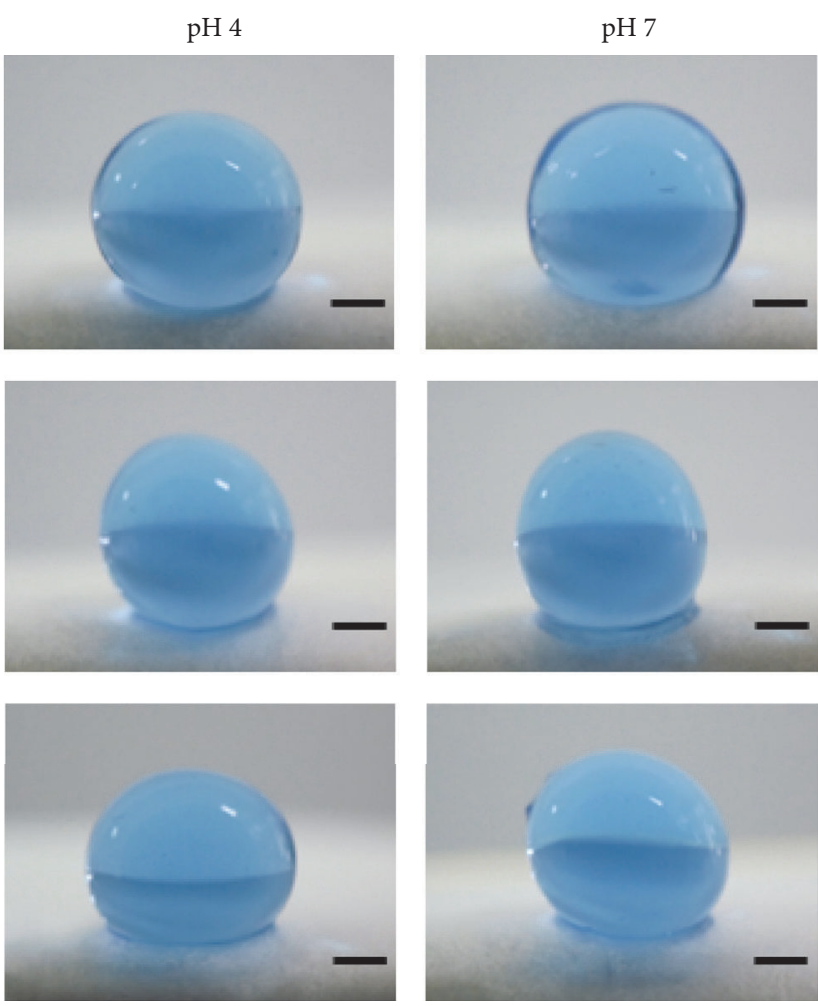
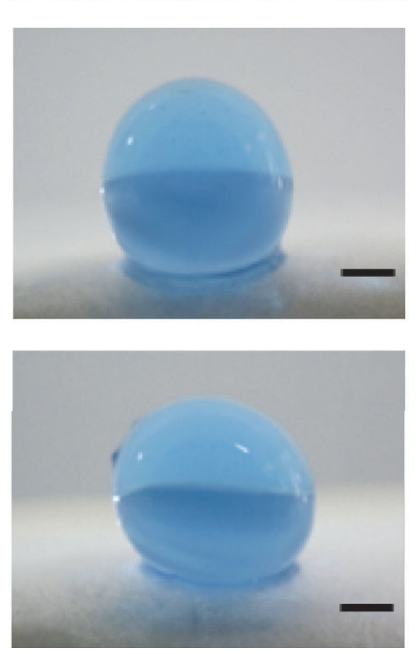

$\mathrm{pH} 10$
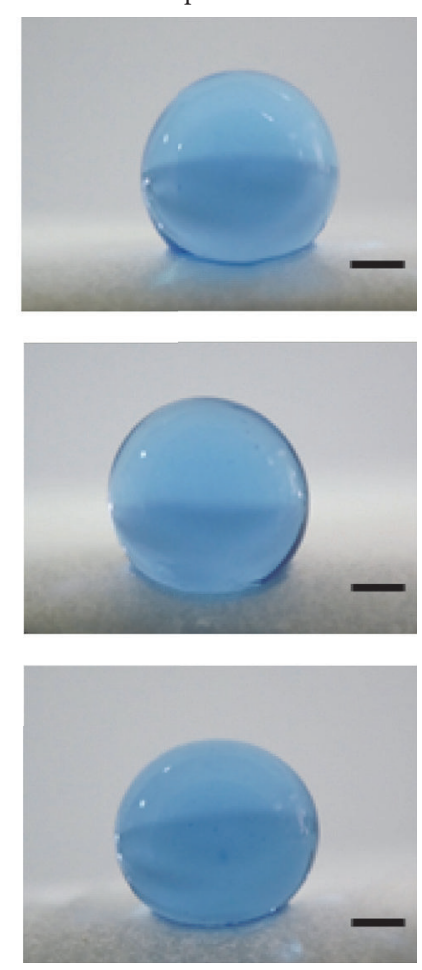

FIGURE 1: Comparison of alginate particle profile versus combinations of $\mathrm{Ca}^{2+}$ concentration and $\mathrm{pH}$ value in a $0.8 \%$ alginate solution. Scale bar $=1 \mathrm{~mm}$.

used to change the interfacial tension so as to obtain aspheric particles $[18,23]$. The $\mathrm{pH}$ value is found as another tunable parameter in alginate gelation process and is directly related to the interfacial tension $[26,29]$. Surprisingly, there are few publications on the shape tailoring of aspheric alginate particles by tuning $\mathrm{pH}$-induced interfacial tension. In this study, variation in interfacial tension is obtained by simply changing $\mathrm{pH}$. Various shaped aspheric alginate particles are made by only tuning the $\mathrm{pH}$ values of gelation solutions, and their release behaviors are investigated as well.

\section{Materials and Methods}

2.1. Materials. Sodium alginate powder was purchased from Sigma Aldrich Chemical Co., Ltd. (Louis, USA), and Coomassie brilliant blue G-250 was obtained from One Star Biotechnology Co., Ltd. (Taipei, Taiwan). Barium chloride dihydrate and anhydrous calcium chloride were supplied from Eco Chemical Co., Ltd. (Taichung, Taiwan). Artificial gastric juice ( $\mathrm{pH}$ 1.2) and intestinal juice ( $\mathrm{pH} 7.5)$ were bought from Sigma Aldrich Chemical Co., Ltd.

2.2. Preparation of Alginate Particles. Respective alginate solutions were prepared in distilled water at concentrations of $0.8 \%, 1.6 \%$, and $2 \%(\mathrm{w} / \mathrm{v})$. The Coomassie brilliant blue G250 was added separately into these three alginate solutions at a concentration of $0.05 \%(\mathrm{w} / \mathrm{v})$ for comparative observation purposes. After homogenization, the alginate solution was filled into a disposable syringe (TERUMOR ${ }^{\circledR}$ Syringe, $3 \mathrm{~mL}$ ) and extruded by a KDS230 syringe pump (KD Scientific Inc., Holliston, MA, USA). The alginate droplets were cross-linked with $\mathrm{BaCl}_{2}$ or $\mathrm{CaCl}_{2}$ solutions to form alginate particles for 5 minutes. There are four predetermined $\mathrm{pH}$ conditions $(\mathrm{pH}$ $1,4,7$, and 10) to address the $\mathrm{pH}$ effects on alginate particle shapes. Moreover, $\mathrm{BaCl}_{2}$ and $\mathrm{CaCl}_{2}$ cross-linkers were presented for three concentrations $(1 \%, 5 \%$, and $10 \% \mathrm{w} / \mathrm{v})$. A digital camera (DP70, Olympus, Taiwan) was employed for imaging to estimate the morphology of alginate particles.

2.3. Release Behavior. Coomassie brilliant blue G-250 was used as a model drug to evaluate the drug release behaviors of the spheric and oblate alginate particles, and subsequently a comparison on the release behaviors is made between the gastric and intestinal cases. At specified time intervals, solutions were drawn to determine the released amount of Coomassie brilliant blue G-250 by a UV/VIS Spectrophotometer (HITACHI U1800, Japan) at a wavelength of $590 \mathrm{~nm}$.

\section{Results and Discussion}

3.1. Effects of $p H$ on Alginate Particle Shapes. To gain a clear understanding, $\mathrm{pH}$ effects on particle shapes for various alginate solution concentrations and various cross-linker types were made. Presented in Figures 1-3 are the photos of the particles, made from $0.8,1.6$, and $2 \%$ alginate solutions, cross-linked with respective concentrations of $\mathrm{CaCl}_{2}$. In Figure 1, higher aspect ratios (ratio of long radius to short radius) are seen in the $\mathrm{pH} 1$ case than others, particularly 

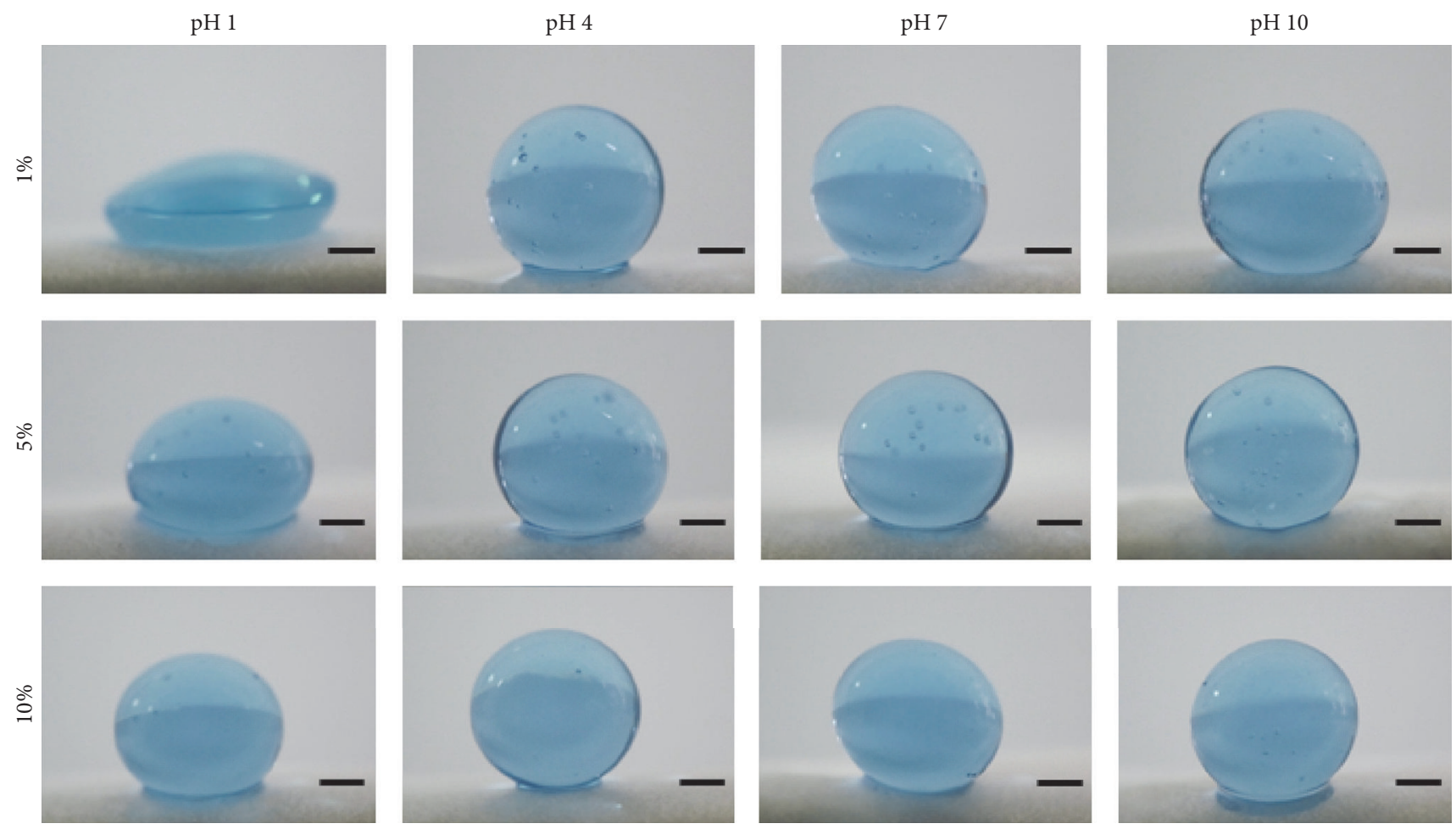

FIGURE 2: Comparison of alginate particle profile versus combinations of $\mathrm{Ca}^{2+}$ concentration and $\mathrm{pH}$ value in a $1.6 \%$ alginate solution. Scale $\mathrm{bar}=1 \mathrm{~mm}$.
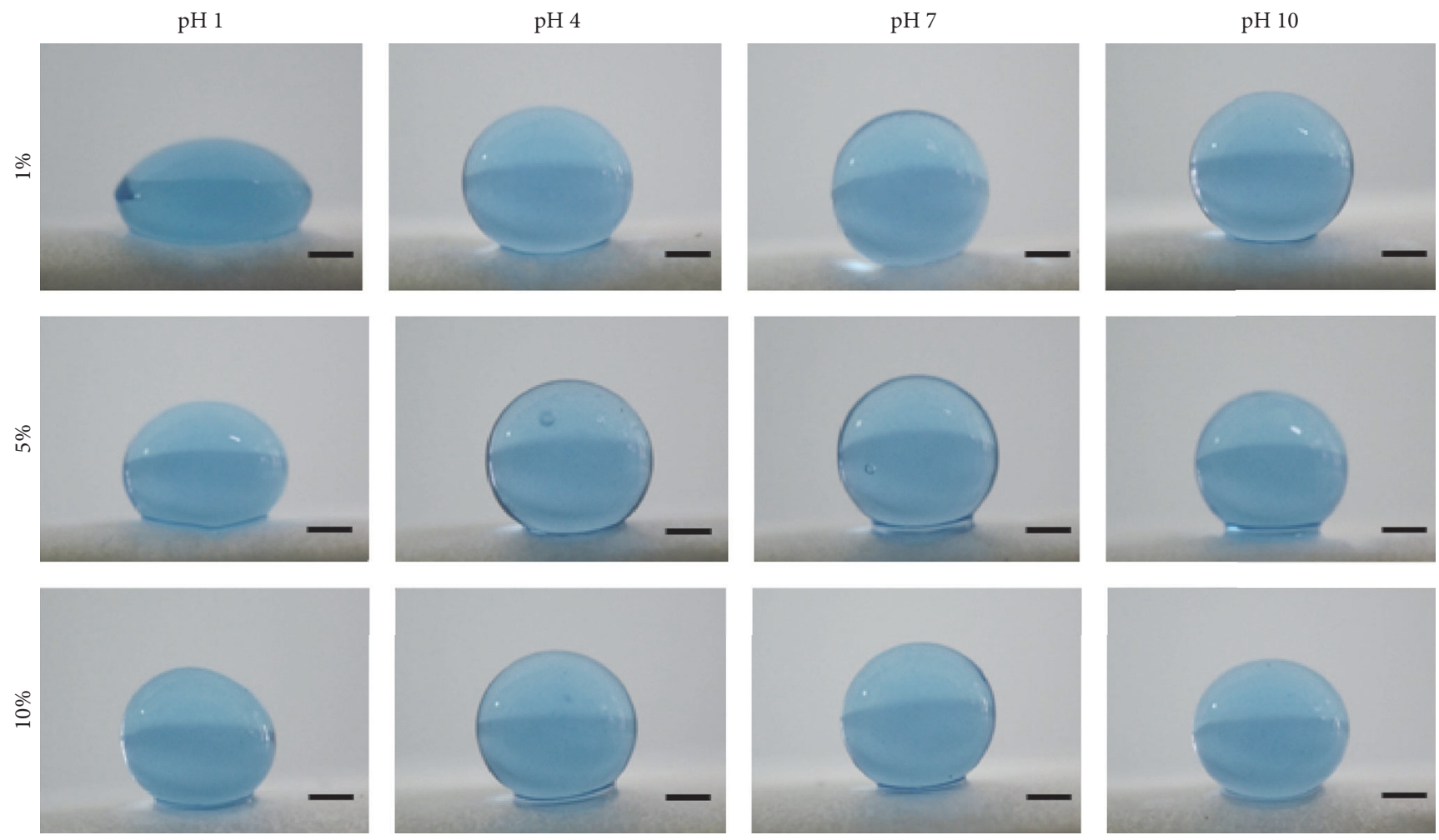

FIGURE 3: Comparison of alginate particle profile versus combinations of $\mathrm{Ca}^{2+}$ concentration and $\mathrm{pH}$ value in a $2 \%$ alginate solution. Scale bar $=1 \mathrm{~mm}$. 


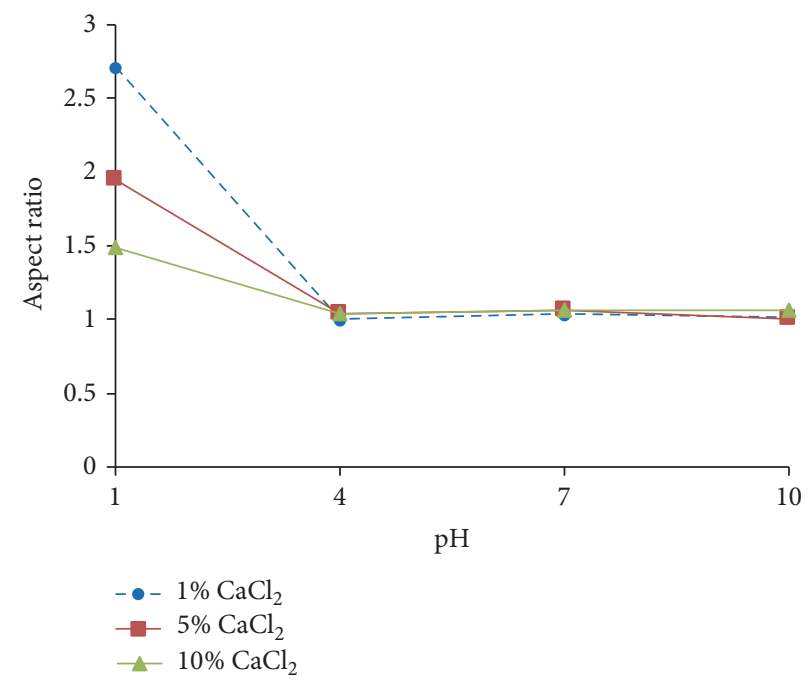

FIGURE 4: Comparison of aspect ratio (ratio of long radius to short radius) in different preparation parameters of $0.8 \%$ alginate particles.
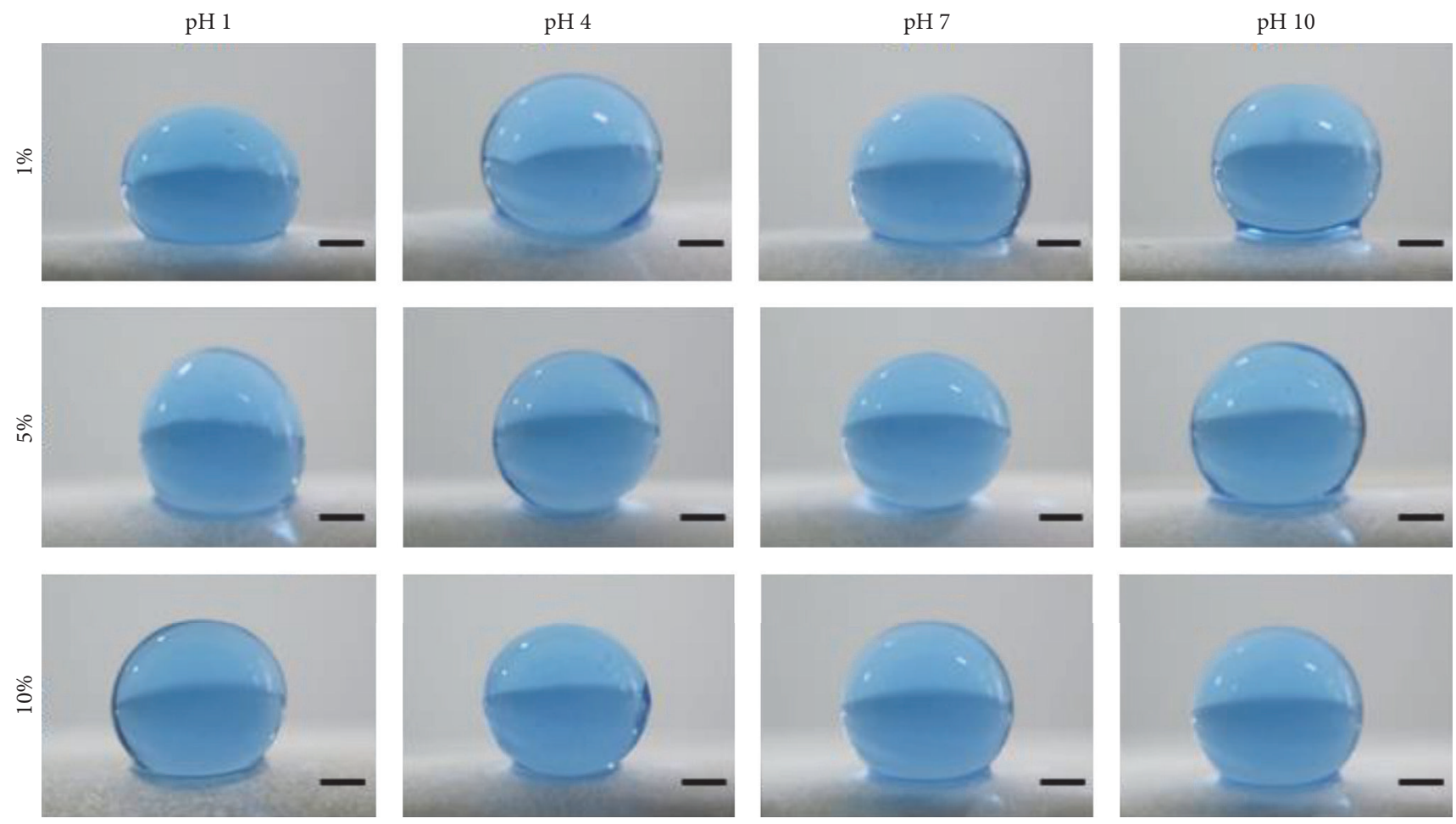

Figure 5: Comparison of alginate particle profile versus combinations of $\mathrm{Ba}^{2+}$ concentration and $\mathrm{pH}$ value in a $0.8 \%$ alginate solution. Scale bar $=1 \mathrm{~mm}$.

for a low $\mathrm{Ca}^{2+}$ concentration. Figure 4 shows that the aspect ratio in Figure 1 increases with the decrease of $\mathrm{pH}$ value and the $\mathrm{Ca}^{2+}$ concentration, and the same observation applies to Figures 2 and 3. However, a low $\mathrm{pH}$ value demonstrates more significant effect on the particle shape at a low alginate and $\mathrm{Ca}^{2+}$ concentration. The alginate particle shape is tailored by the balance between the polymer viscosity and the interfacial tension [26]. A lower $\mathrm{pH}$ gelation solution gives rise to a lower interfacial tension [30] and further results in an oblate particle with a higher aspect ratio.

Since gel-forming ability of alginate relies on the G-blocks binding divalent cations [31], there are an inadequate number of divalent cations in a low concentration of cross-linker to bind G-blocks and inadequate number of G-blocks in a low 

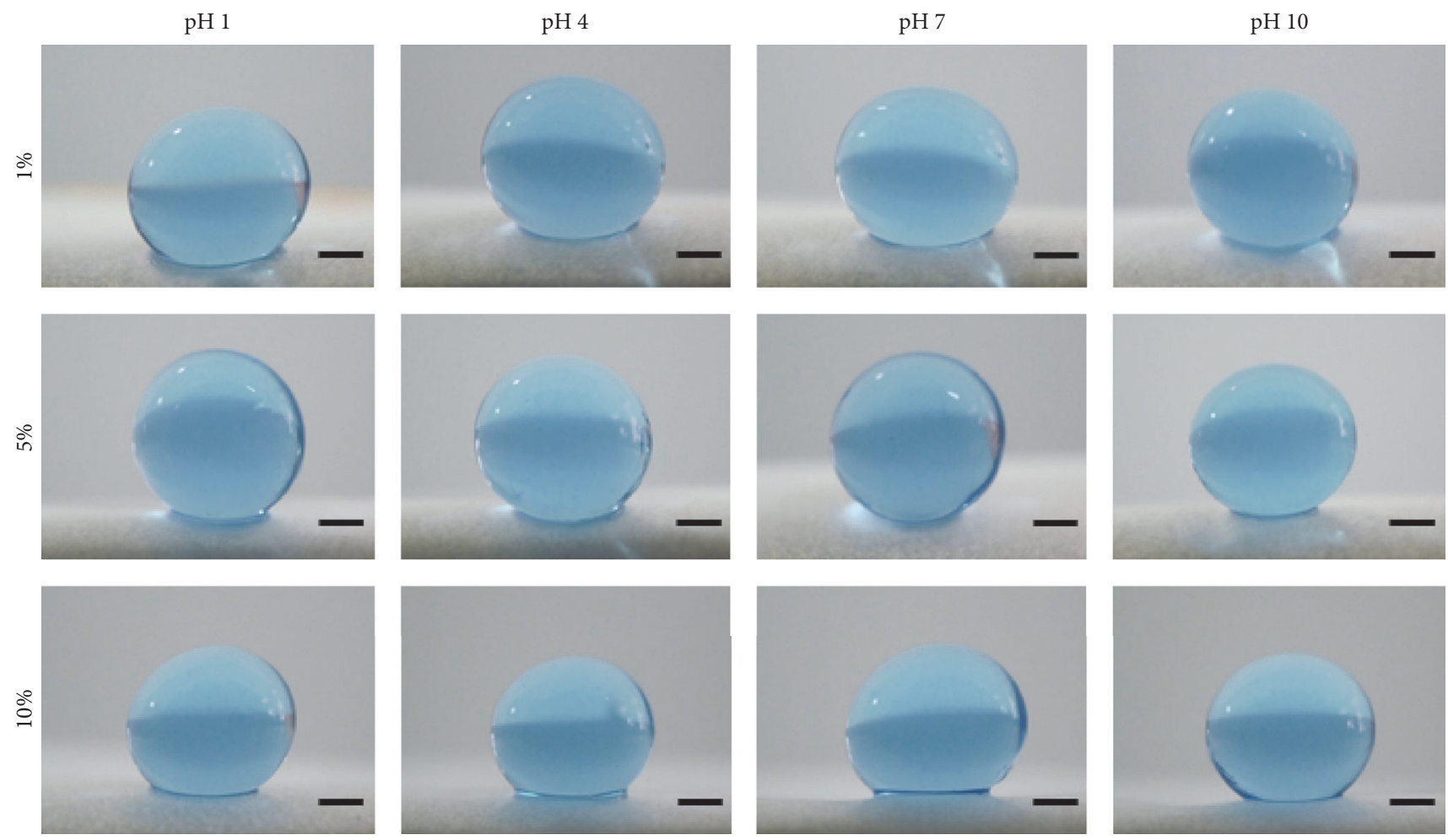

FIGURE 6: Comparison of alginate particle profile versus combinations of $\mathrm{Ba}^{2+}$ concentration and $\mathrm{pH}$ value in a $1.6 \%$ alginate solution. Scale bar $=1 \mathrm{~mm}$.
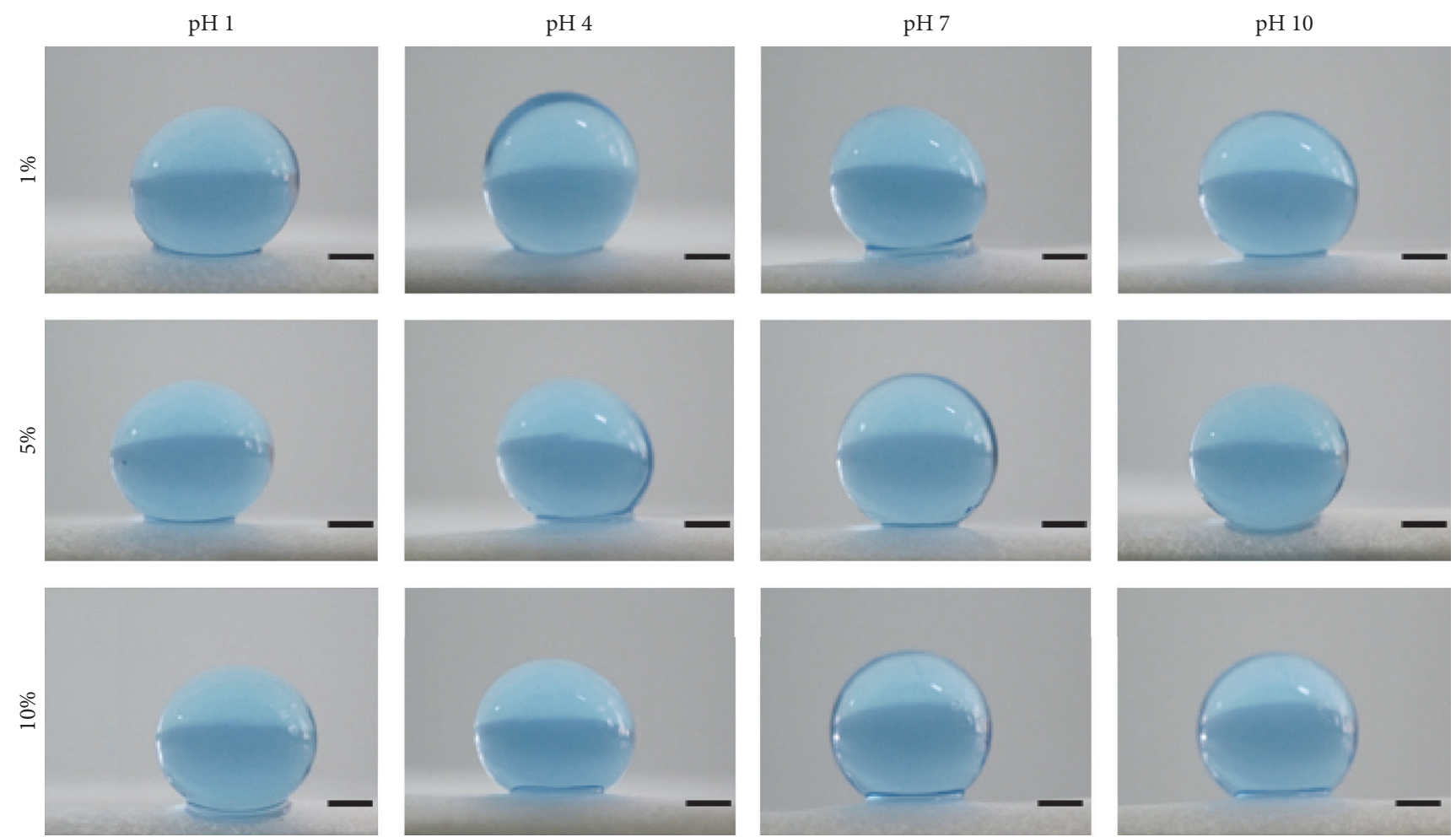

Figure 7: Comparison of alginate particle profile versus combinations of $\mathrm{Ba}^{2+}$ concentration and $\mathrm{pH}$ value in a $2 \%$ alginate solution. Scale bar $=1 \mathrm{~mm}$. 

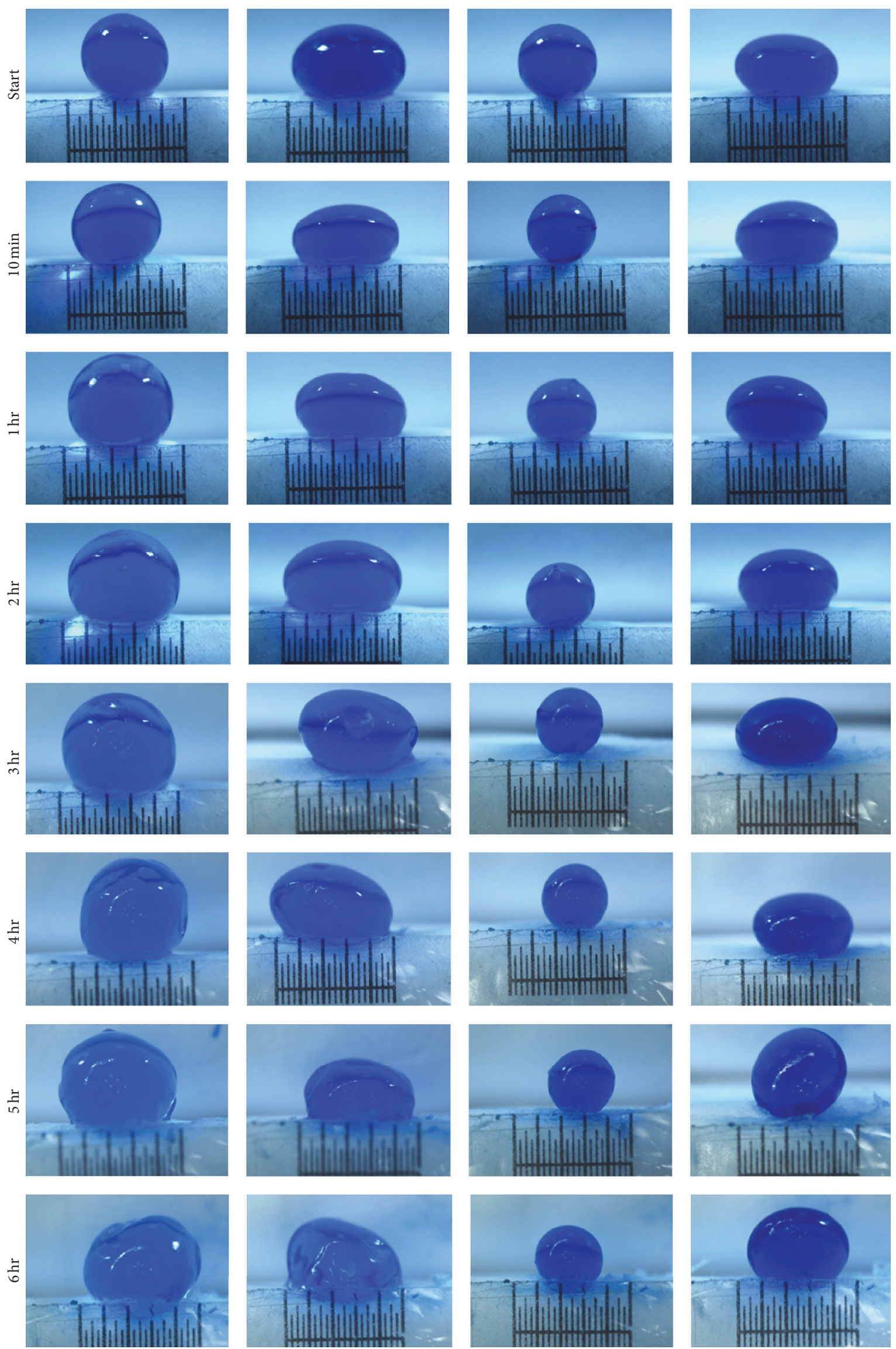

Sphere/intestinal juice

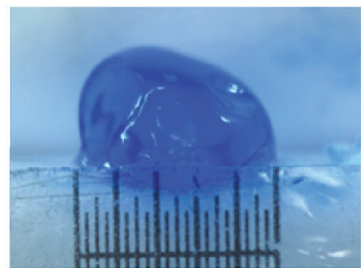

Oblateness/intestinal juice

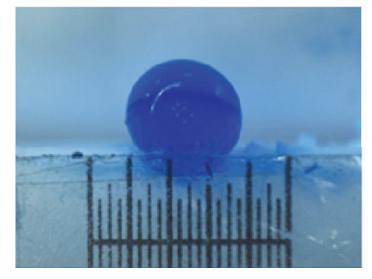

Sphere/gastric juice

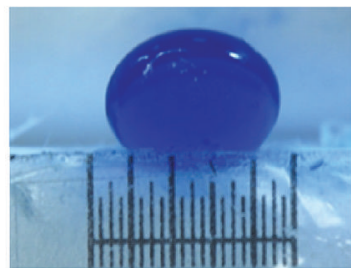

Oblateness/gastric juice

FIGURE 8: Dynamic shape changes of spheric and oblate alginate particles in intestinal and gastric juices. 
alginate concentration for binding. Besides, there is a low viscosity for the dilute alginate solution. Hence, there exist oblate particles in low concentrations of alginate and crosslinker. This phenomenon is obvious at a low $\mathrm{pH}$ value, but not significant when $\mathrm{pH}$ is greater than 4 .

Demonstrated in Figures 5-7 are the photos of the particles cross-linked with $\mathrm{Ba}^{2+}$ under the aforementioned alginate conditions, namely, $0.8,1.6$, and $2 \%$. In contrast to those cross-linked with $\mathrm{Ca}^{2+}$ in Figures 1-3, there are no significant shape changes in Figures 5-7. This is simply due to the reason that alginate has a higher affinity with $\mathrm{Ba}^{2+}$ than with $\mathrm{Ca}^{2+}[32]$, and stable shaped particles are formed when cross-linked regardless of the change in the $\mathrm{pH}$-induced interfacial tension.

\subsection{Dynamic Shape Changes and Swelling Ratio in Gastric} and Intestinal Juices. Figure 8 shows the dynamic shapes of oblate and spheric alginate particles immersed in gastric and intestinal juices for as long as 6 hours. Results indicate that the particles in the intestinal juice became easily collapsed, while in contrast there was no significant shape change in the gastric juice. Both spheric and oblate particles in intestinal juice swelled gradually over time and began to collapse 4 hours later. In a good agreement with previous reports, alginate particles disintegrated in alkaline, but not in acidic, media [33]. The pKa values of mannuronic and guluronic acid residues of alginate are measured to be 3.38 and 3.65 , respectively [34]. With a $\mathrm{pH}$ value below the $\mathrm{pKa}$ of the uronic acid, alginate gels are stabilized by an intermolecular hydrogen bonding network [35]. Therefore, alginate particles are broken down easily in intestinal, but stable in gastric, juice.

Figure 9 reveals a swelling ratio comparison between alginate particles in gastric and intestinal juices. A higher swelling ratio of the particles is seen in the intestinal than in the gastric cases. In a good agreement with a previous study, there is a higher swelling degree in a simulated enteric than in a gastric environment [36]. The higher swelling ratio can be attributed to a chain expansion from the ionic carboxylate groups of alginate at a higher $\mathrm{pH}$ value [35].

3.3. Drug Release Behavior. Exhibited in Figure 10 are the release behaviors of Coomassie brilliant blue G-250 encapsulated in oblate and spheric alginate particles. The $1.6 \%$ alginate and $5 \% \mathrm{Ca}^{2+}$ were used, and $\mathrm{pH} 1$ and 7 were applied to obtain oblate and spheric particles, respectively. It is experimentally demonstrated that both oblate and spheric particles have a higher drug release rate in the intestinal than in the gastric juice. It is due to the change in the alginate microstructure in solutions under different $\mathrm{pH}$ conditions. As a $\mathrm{pH}$-responsive polymer [37], alginate will shrink in a low $\mathrm{pH}$ medium but swells or further dissolves in a high $\mathrm{pH}$ one. Therefore, a relatively intact microstructure of alginate in the gastric juice yields a relatively slow release rate. In this study, a higher drug release rate is seen from oblate than from spheric particles, since an oblate particle is of a larger surface area than a spheric one [38]. As a consequence, the alginate particle shape is characterized as a significant parameter through drug release profile in pharmaceutical kinetics.

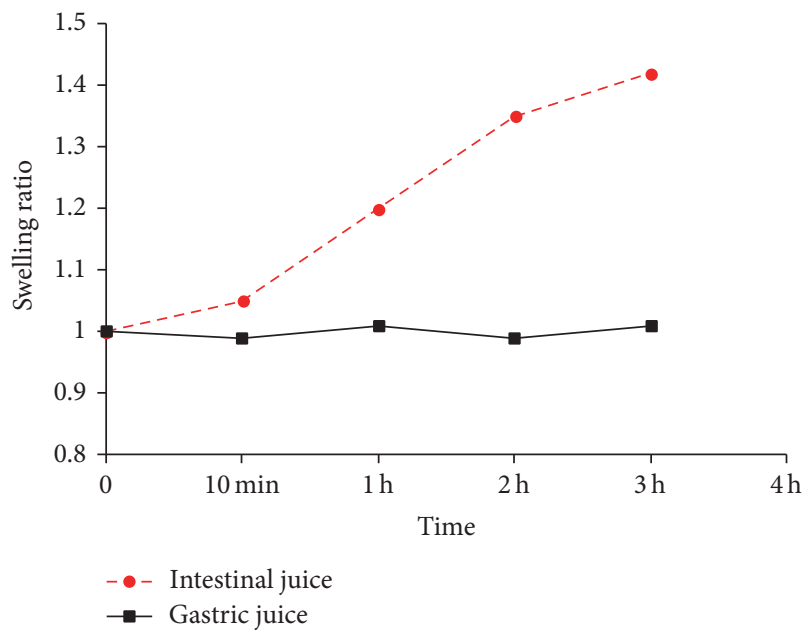

FIGURE 9: Swelling ratio comparison for spheric alginate particles between the intestinal and gastric cases.

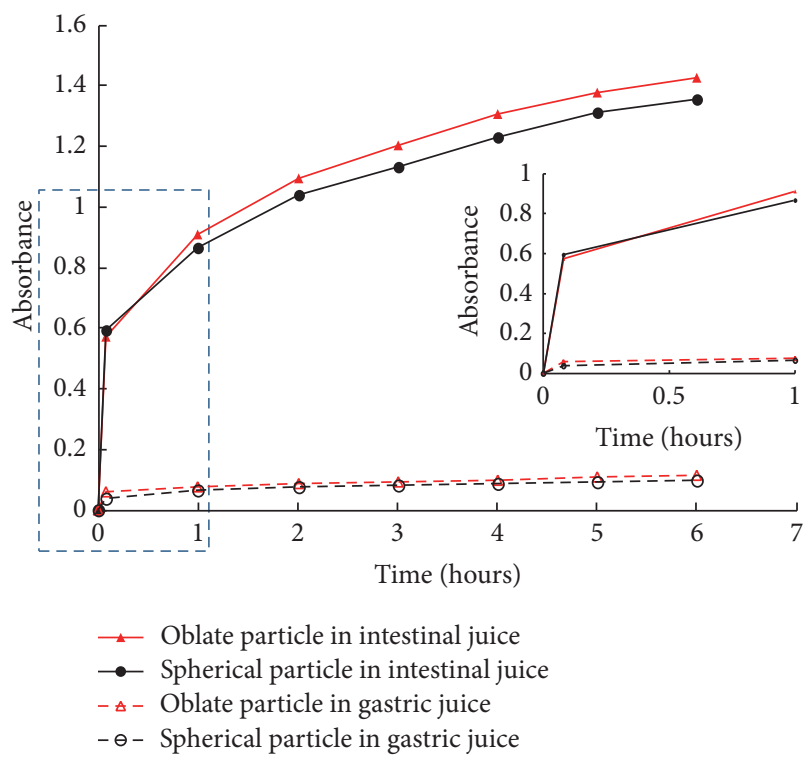

FIGURE 10: Release profile comparison of Coomassie brilliant blue G-250 encapsulated in spheric and oblate alginate particles immersed in the intestinal and gastric juices.

\section{Conclusion}

This study demonstrates $\mathrm{pH}$-tuned shape tailoring of alginate particles and analysis on release behaviors. Alginate droplets contained in low $\mathrm{pH}$ gelation solutions tend to turn into oblate alginate particles. Oblate particles with a higher aspect ratio are experimentally demonstrated in lower concentrations of both alginate and $\mathrm{Ca}^{2+}$ cross-linker. In contrast, the $\mathrm{Ba}^{2+}$ cross-linker demonstrates little influence on the alginate particles. In intestinal juice, spheric and oblate particles swelled gradually over time and began to collapse 4 hours later. However, there was no significant shape change in the gastric juice cases. A higher release rate is seen in the intestinal than in the gastric juice. Additionally, a higher 
release rate is demonstrated in the oblate case than in the spheric counterpart since a sphere has a smaller surface area than other shaped particles. This research finding could be seen as informative when applied to successive studies on the related alginate issue.

\section{Competing Interests}

The authors declare no conflict of interests.

\section{Acknowledgments}

This work was supported by a grant from the Ministry of Science and Technology, Taiwan, under Grant no. MOST 1052221-E-239-031.

\section{References}

[1] C. Wischke, C. Schneider, A. T. Neffe, and A. Lendlein, "Polyalkylcyanoacrylates as in situ formed diffusion barriers in multimaterial drug carriers," Journal of Controlled Release, vol. 169, no. 3, pp. 321-328, 2013.

[2] C.-C. Chen, C.-L. Fang, S. A. Al-Suwayeh, Y.-L. Leu, and J.Y. Fang, "Transdermal delivery of selegiline from alginatepluronic composite thermogels," International Journal of Pharmaceutics, vol. 415, no. 1-2, pp. 119-128, 2011.

[3] P. C. Balaure, E. Andronescu, A. M. Grumezescu et al., "Fabrication, characterization and in vitro profile based interaction with eukaryotic and prokaryotic cells of alginate-chitosan-silica biocomposite," International Journal of Pharmaceutics, vol. 441, no. 1-2, pp. 555-561, 2013.

[4] S. Hua, H. Ma, X. Li, H. Yang, and A. Wang, "pH-sensitive sodium alginate/poly(vinyl alcohol) hydrogel beads prepared by combined $\mathrm{Ca}^{2+}$ crosslinking and freeze-thawing cycles for controlled release of diclofenac sodium," International Journal of Biological Macromolecules, vol. 46, no. 5, pp. 517-523, 2010.

[5] A. K. Nayak, M. S. Hasnain, S. Beg, and M. I. Alam, "Mucoadhesive beads of gliclazide: design, development, and evaluation," ScienceAsia, vol. 36, no. 4, pp. 319-325, 2010.

[6] A. K. Nayak and D. Pal, "Development of pH-sensitive tamarind seed polysaccharide-alginate composite beads for controlled diclofenac sodium delivery using response surface methodology," International Journal of Biological Macromolecules, vol. 49, no. 4, pp. 784-793, 2011.

[7] M. D. De’Nobili, L. M. Curto, J. M. Delfino, M. Soria, E. N. Fissore, and A. M. Rojas, "Performance of alginate films for retention of L-(+)-ascorbic acid," International Journal of Pharmaceutics, vol. 450, no. 1-2, pp. 95-103, 2013.

[8] Ý. A. Mørch, I. Donati, B. L. Strand, and G. Skjåk-Bræk, "Effect of $\mathrm{Ca}^{2+}, \mathrm{Ba}^{2+}$, and $\mathrm{Sr}^{2+}$ on alginate microbeads," Biomacromolecules, vol. 7, no. 5, pp. 1471-1480, 2006.

[9] K. Y. Lee and D. J. Mooney, "Alginate: properties and biomedical applications," Progress in Polymer Science, vol. 37, no. 1, pp. 106126, 2012.

[10] P. Degen, S. Leick, F. Siedenbiedel, and H. Rehage, "Magnetic switchable alginate beads," Colloid and Polymer Science, vol. 290, no. 2, pp. 97-106, 2012.

[11] L. Capretto, S. Mazzitelli, G. Luca, and C. Nastruzzi, "Preparation and characterization of polysaccharidic microbeads by a microfluidic technique: application to the encapsulation of Sertoli cells," Acta Biomaterialia, vol. 6, no. 2, pp. 429-435, 2010.
[12] L. Liu, F. Wu, X.-J. Ju et al., "Preparation of monodisperse calcium alginate microcapsules via internal gelation in microfluidic-generated double emulsions," Journal of Colloid and Interface Science, vol. 404, pp. 85-90, 2013.

[13] H. Song, W. Yu, M. Gao, X. Liu, and X. Ma, "Microencapsulated probiotics using emulsification technique coupled with internal or external gelation process," Carbohydrate Polymers, vol. 96, no. 1, pp. 181-189, 2013.

[14] K. I. Draget and C. Taylor, "Chemical, physical and biological properties of alginates and their biomedical implications," Food Hydrocolloids, vol. 25, no. 2, pp. 251-256, 2011.

[15] C. A. Hoesli, K. Raghuram, R. L. J. Kiang et al., "Pancreatic cell immobilization in alginate beads produced by emulsion and internal gelation," Biotechnology and Bioengineering, vol. 108, no. 2, pp. 424-434, 2011.

[16] A. Sohail, M. S. Turner, A. Coombes, T. Bostrom, and B. Bhandari, "Survivability of probiotics encapsulated in alginate gel microbeads using a novel impinging aerosols method," International Journal of Food Microbiology, vol. 145, no. 1, pp. 162-168, 2011.

[17] M.-H. Wu and W.-C. Pan, "Development of microfluidic alginate microbead generator tunable by pulsed airflow injection for the microencapsulation of cells," Microfluidics and Nanofluidics, vol. 8, no. 6, pp. 823-835, 2010.

[18] S. Ungphaiboon, D. Attia, G. Gomez D’Ayala, P. Sansongsak, F. Cellesi, and N. Tirelli, "Materials for microencapsulation: what toroidal particles ('doughnuts') can do better than spherical beads," Soft Matter, vol. 6, no. 17, pp. 4070-4083, 2010.

[19] D. Dendukuri and P. S. Doyle, "The synthesis and assembly of polymeric microparticles using microfluidics," Advanced Materials, vol. 21, no. 41, pp. 4071-4086, 2009.

[20] S. Venkataraman, J. L. Hedrick, Z. Y. Ong et al., "The effects of polymeric nanostructure shape on drug delivery," Advanced Drug Delivery Reviews, vol. 63, no. 14-15, pp. 1228-1246, 2011.

[21] Y.-S. Lin, C.-H. Yang, Y.-Y. Hsu, and C.-L. Hsieh, "Microfluidic synthesis of tail-shaped alginate microparticles using slow sedimentation," Electrophoresis, vol. 34, no. 3, pp. 425-431, 2013.

[22] Y. Hu, Q. Wang, J. Wang, J. Zhu, H. Wang, and Y. Yang, "Shape controllable microgel particles prepared by microfluidic combining external ionic crosslinking," Biomicrofluidics, vol. 6, no. 2, Article ID 026502, 2012.

[23] C.-H. Yang, K.-S. Huang, C.-Y. Wang, Y.-Y. Hsu, F.-R. Chang, and Y.-S. Lin, "Microfluidic-assisted synthesis of hemispherical and discoidal chitosan microparticles at an oil/water interface," Electrophoresis, vol. 33, no. 21, pp. 3173-3180, 2012.

[24] S. Muro, C. Garnacho, J. A. Champion et al., "Control of endothelial targeting and intracellular delivery of therapeutic enzymes by modulating the size and shape of ICAM-1-targeted carriers," Molecular Therapy, vol. 16, no. 8, pp. 1450-1458, 2008.

[25] N. Doshi, B. Prabhakarpandian, A. Rea-Ramsey, K. Pant, S. Sundaram, and S. Mitragotri, "Flow and adhesion of drug carriers in blood vessels depend on their shape: a study using model synthetic microvascular networks," Journal of Controlled Release, vol. 146, no. 2, pp. 196-200, 2010.

[26] J.-W. Yoo and S. Mitragotri, "Polymer particles that switch shape in response to a stimulus," Proceedings of the National Academy of Sciences of the United States of America, vol. 107, no. 25, pp. 11205-11210, 2010.

[27] D. Kregiel, J. Berlowska, and W. Ambroziak, "Growth and metabolic activity of conventional and non-conventional yeasts immobilized in foamed alginate," Enzyme and Microbial Technology, vol. 53, no. 4, pp. 229-234, 2013. 
[28] C. H. Choi, J. Lee, K. Yoon et al., "Surface-tension-induced synthesis of complex particles using confined polymeric fluids," Angewandte Chemie International Edition, vol. 122, pp. 79147918, 2010.

[29] D. K. Beaman, E. J. Robertson, and G. L. Richmond, “Ordered polyelectrolyte assembly at the oil-water interface," Proceedings of the National Academy of Sciences of the United States of America, vol. 109, no. 9, pp. 3226-3231, 2012.

[30] V. D. Kiosseoglou and P. Sherman, "The influence of egg yolk lipoproteins on the rheology and stability of $\mathrm{O} / \mathrm{W}$ emulsions and mayonnaise-2. Interfacial tension-time behaviour of egg yolk lipoproteins at the groundnut oil-water interface," Colloid \& Polymer Science, vol. 261, no. 6, pp. 502-507, 1983.

[31] G. Orive, R. M. Hernández, A. Rodríguez Gascón, and J. Luis Pedraz, "Encapsulation of cells in alginate gels," in Immobilization of Enzymes and Cells, vol. 22 of Methods in Biotechnology, pp. 345-355, 2006.

[32] I. C. M. Kwan, Y.-M. She, and G. Wu, "Nuclear magnetic resonance and mass spectrometry studies of $2^{\prime}, 3^{\prime}, 5^{\prime}$-O-triacetylguanosine self-assembly in the presence of alkaline earth metal ions $\left(\mathrm{Ca}^{2+}, \mathrm{Sr}^{2+}, \mathrm{Ba}^{2+}\right)$," Canadian Journal of Chemistry, vol. 89, no. 7, pp. 835-844, 2011.

[33] M. A. T. Rasel and M. Hasan, "Formulation and evaluation of floating alginate beads of diclofenac sodium," Dhaka University Journal of Pharmaceutical Sciences, vol. 11, no. 1, pp. 29-35, 2012.

[34] N. L. Francis, P. M. Hunger, A. E. Donius et al., "An icetemplated, linearly aligned chitosan-alginate scaffold for neural tissue engineering," Journal of Biomedical Materials Research Part A, vol. 101, no. 12, pp. 3493-3503, 2013.

[35] S. N. Pawar and K. J. Edgar, "Alginate derivatization: a review of chemistry, properties and applications," Biomaterials, vol. 33, no. 11, pp. 3279-3305, 2012.

[36] R. M. Lucinda-Silva, H. R. N. Salgado, and R. C. Evangelista, "Alginate-chitosan systems: in vitro controlled release of triamcinolone and in vivo gastrointestinal transit," Carbohydrate Polymers, vol. 81, no. 2, pp. 260-268, 2010.

[37] P. Mukhopadhyay, K. Sarkar, S. Soam, and P. P. Kundu, "Formulation of $\mathrm{pH}$-responsive carboxymethyl chitosan and alginate beads for the oral delivery of insulin," Journal of Applied Polymer Science, vol. 129, no. 2, pp. 835-845, 2013.

[38] T. W. Wong, "Alginate graft copolymers and alginate-coexcipient physical mixture in oral drug delivery," Journal of Pharmacy and Pharmacology, vol. 63, no. 12, pp. 1497-1512, 2011. 

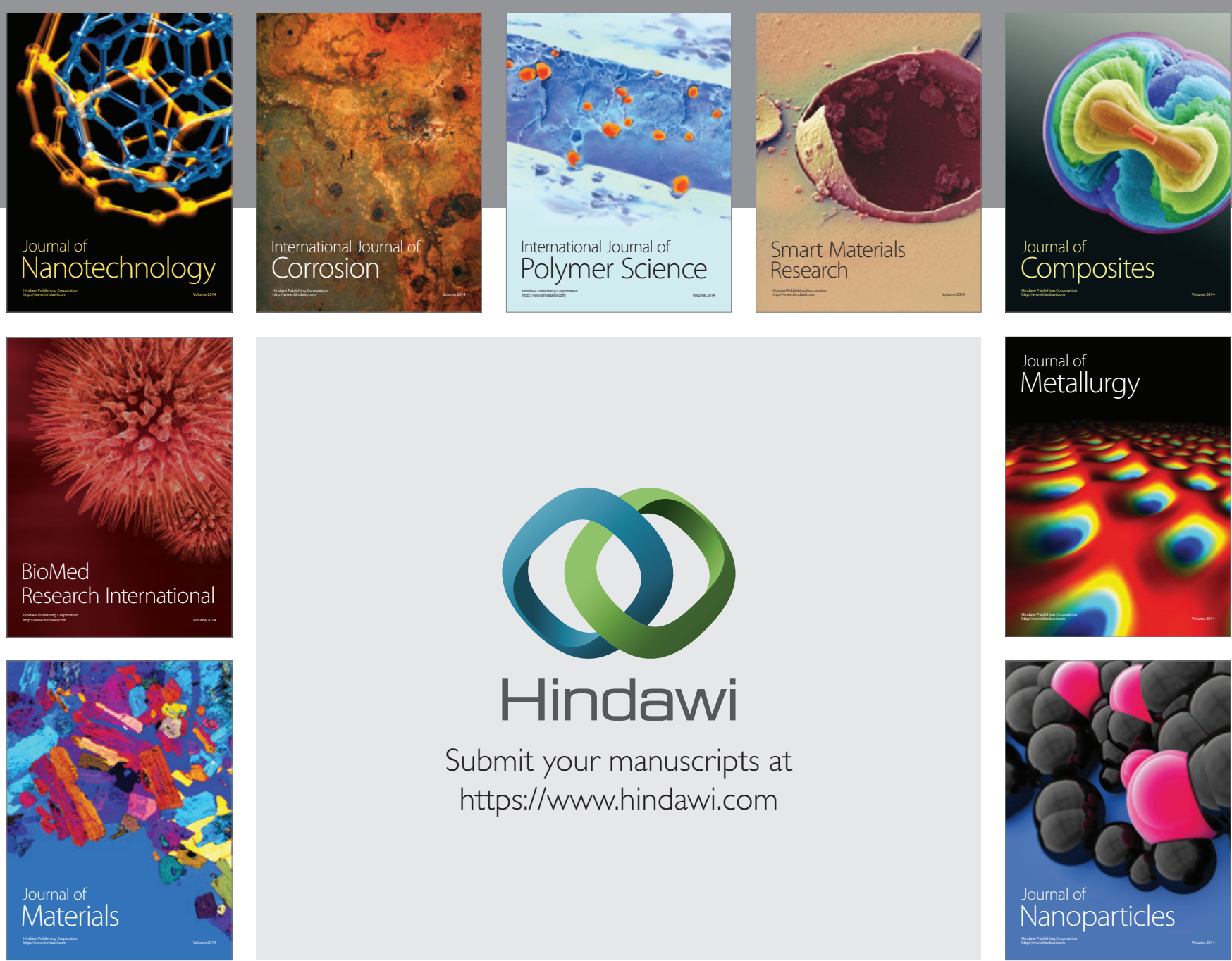

\section{Hindawi}

Submit your manuscripts at

https://www.hindawi.com

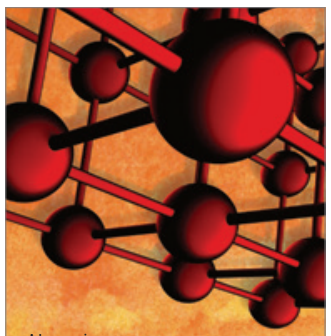

Materials Science and Engineering
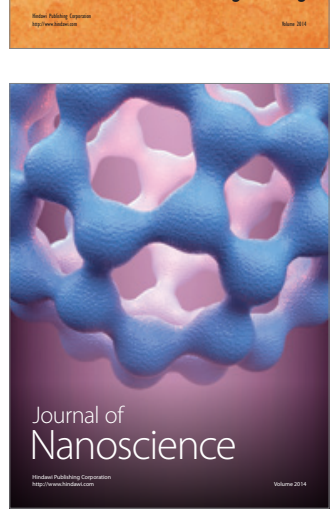
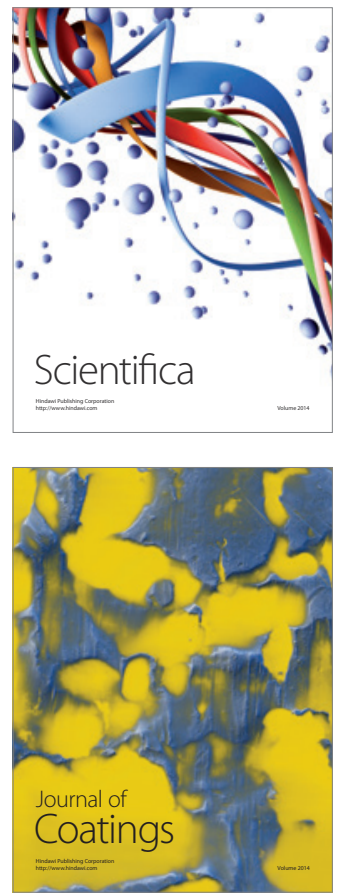
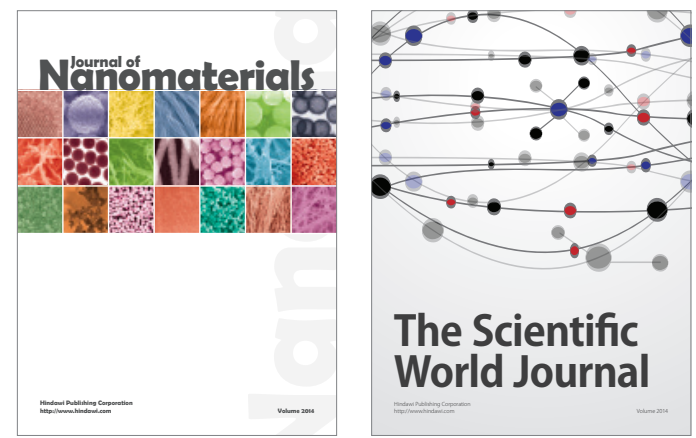

The Scientific World Journal
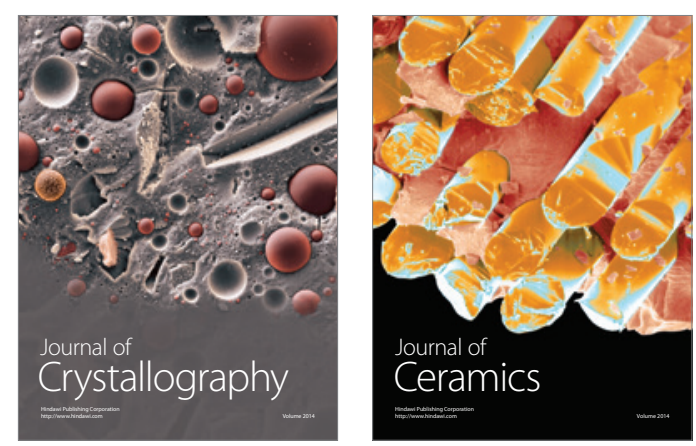
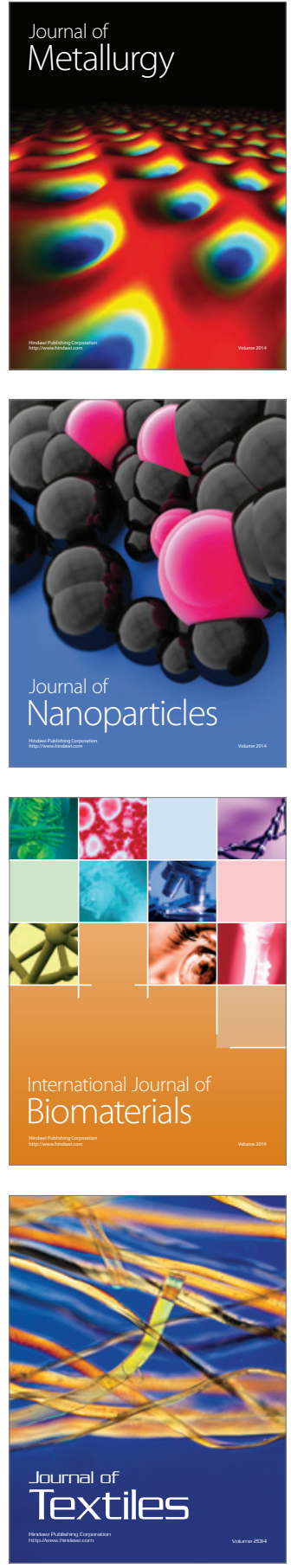